\title{
Origin of Tropospheric Air Masses in the Tropical West Pacific identified by Balloon- borne Ozone and Water Vapor Measurements from Palau
}

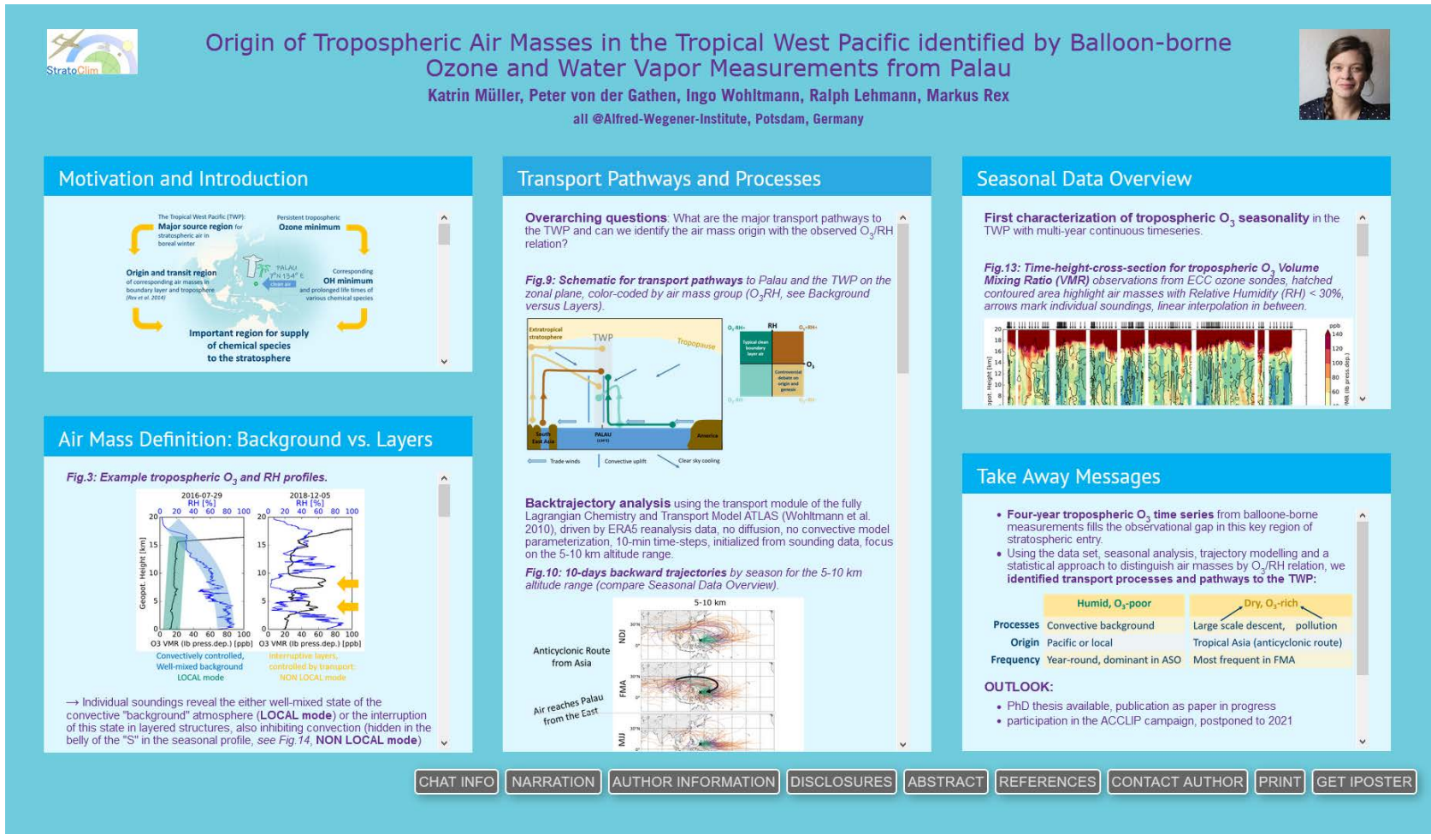

Katrin Müller, Peter von der Gathen, Ingo Wohltmann, Ralph Lehmann, Markus Rex all @Alfred-Wegener-Institute, Potsdam, Germany

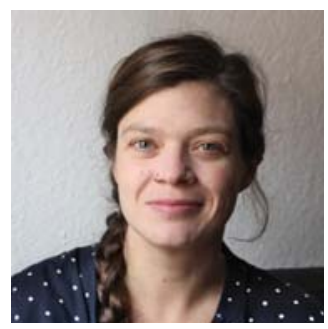

PRESENTED AT: 


\section{MOTIVATION AND INTRODUCTION}

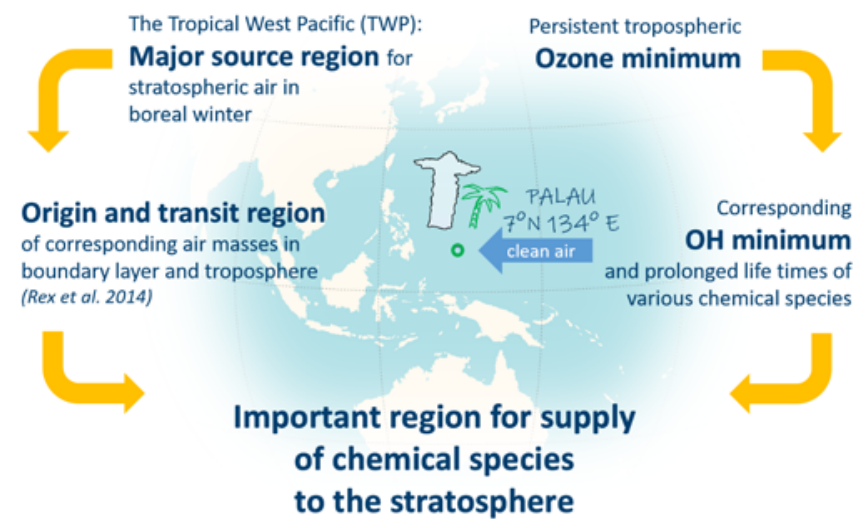

Key feature of the clean TWP troposphere: close coupling of the $\mathrm{O}_{3}$ concentration and oxidizing capacity $(\mathrm{OH})$, influencing overall transport of chemical species to the stratosphere:

$$
\begin{gathered}
\mathrm{O}_{3}+h v \rightarrow O\left({ }^{1} D\right)+\mathrm{O}_{2} \\
O\left({ }^{1} D\right)+\mathrm{H}_{2} \mathrm{O} \rightarrow \mathrm{OH}+\mathrm{OH}
\end{gathered}
$$

To improve the limited availability of tropospheric $\mathrm{O}_{3}$ observations from this key region, the Palau Atmospheric Observatory was established in 2016 as part of the EU-project StratoClim.

Fig.1: Palau Atmospheric Observatory (Photo: Ingo Beninga).
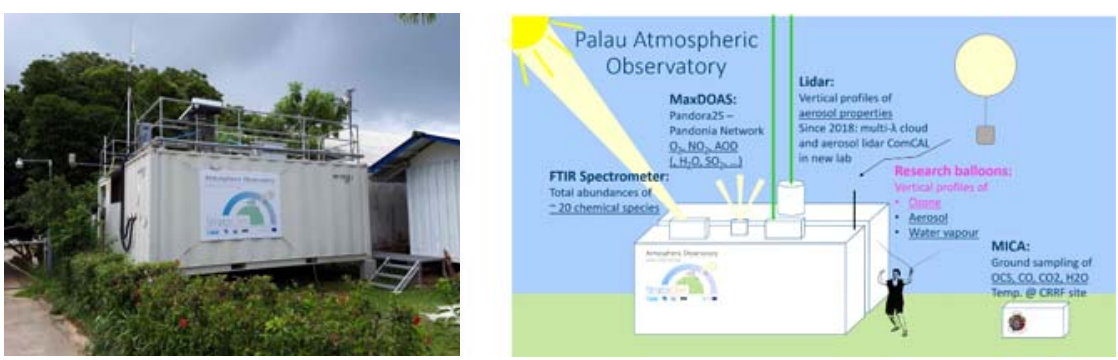

The data set presented here consists of 145 soundings from ECC (Electrochemical Concentration Cell) ozone- and radiosondes (SPC model 6A, Vaisala RS92/41), from 01/2016 until 10/2019, obtained in bi-weekly frequency or intensive measurement campaigns.

Fig.2: Weather balloon launch with ECC ozonesonde (Photos: Jürgen Graeser, Katrin Müller). 


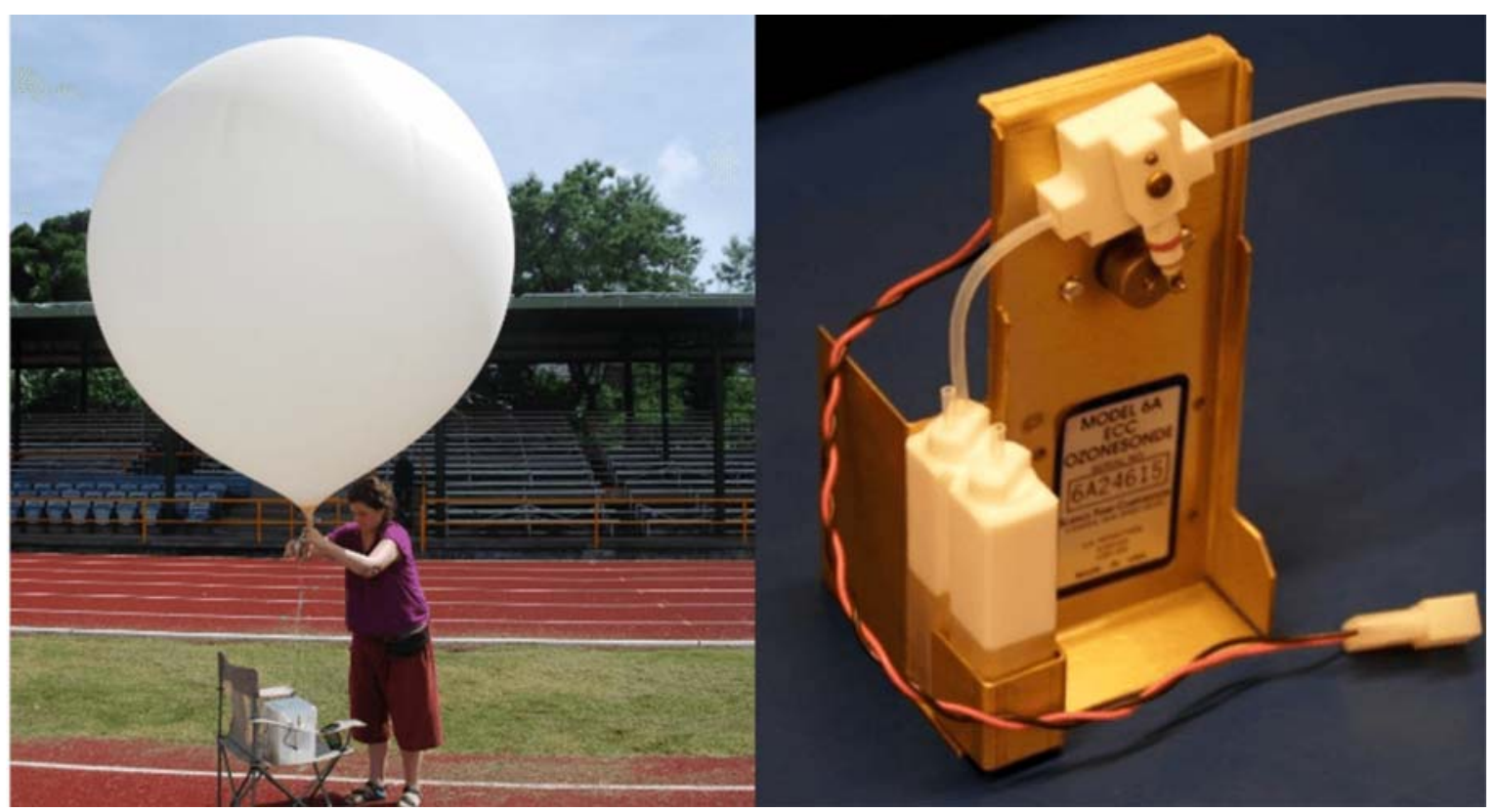




\section{AIR MASS DEFINITION: BACKGROUND VS. LAYERS}

Fig.3: Example tropospheric $\mathrm{O}_{3}$ and $\mathrm{RH}$ profiles.
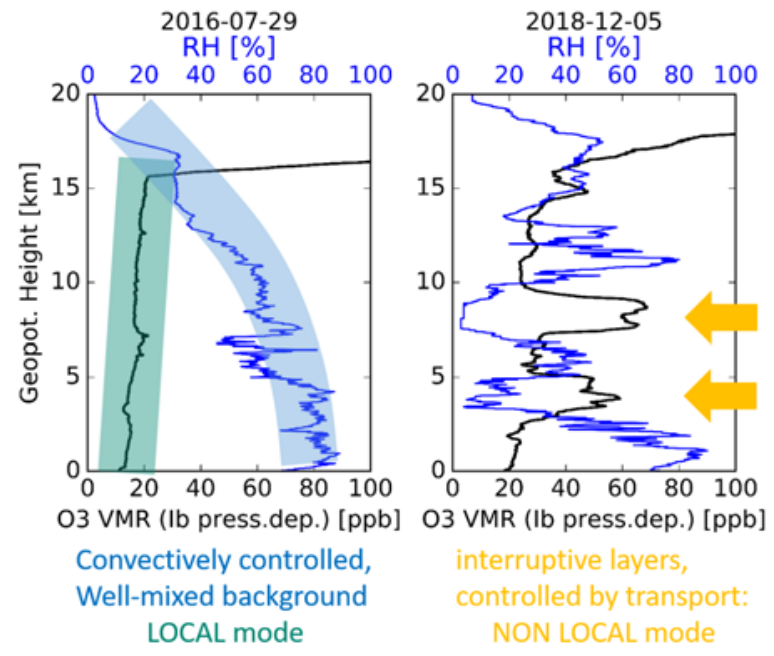

$\rightarrow$ Individual soundings reveal the either well-mixed state of the convective "background" atmosphere (LOCAL mode) or the interruption of this state in layered structures, also inhibiting convection (hidden in the belly of the "S" in the seasonal profile, see Fig.14, NON LOCAL mode)

\section{Underlying processes:}

- Local boundary layer air masses lacking pollution and therefore $\mathbf{l o w}$ in $\mathbf{O}_{\mathbf{3}}$ are lifted locally by convection.

- No known mechanism for in situ production of high $\mathbf{O}_{\mathbf{3}}$ or dehydration in the mid-troposphere - origin either transport from the (extratropical) stratosphere or non-local ground pollution, lifted convectively in the area of origin then undergoing dehydration during transport, e.g. via large-scale descent and radiative cooling (see Fig.9, compare Dessler and Minschwaner, 2007; Anderson et al. 2016).

Fig.4: Example of the statistical approach to determine a background profile and identify deviating layers from the entire dataset.

Example for monthly statistics

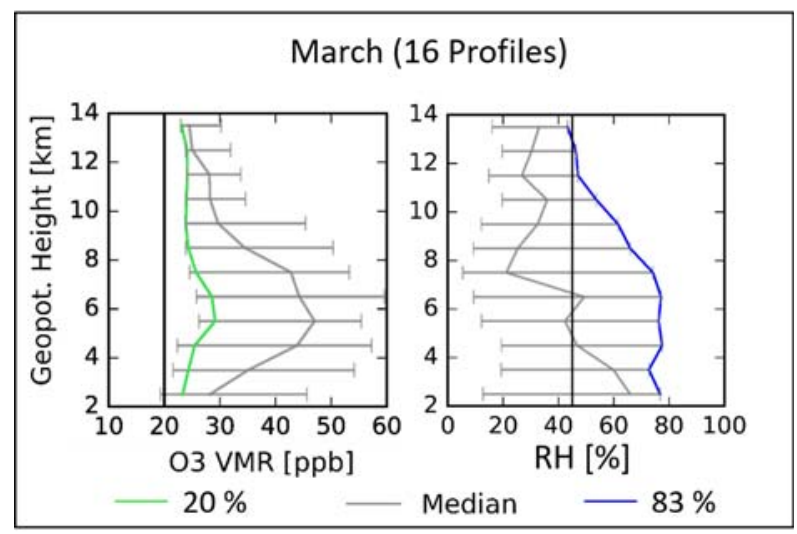

$\rightarrow$ Background definition: the monthly $20^{\text {th }}\left(\mathrm{O}_{3}\right)$ and $83^{\text {rd }}(\mathrm{RH})$ quantile, altitude-dependent.

Fig.5: Free-tropospheric (3-14 km) $\mathrm{O}_{3} / \mathrm{RH}$ relation for the full data set. 


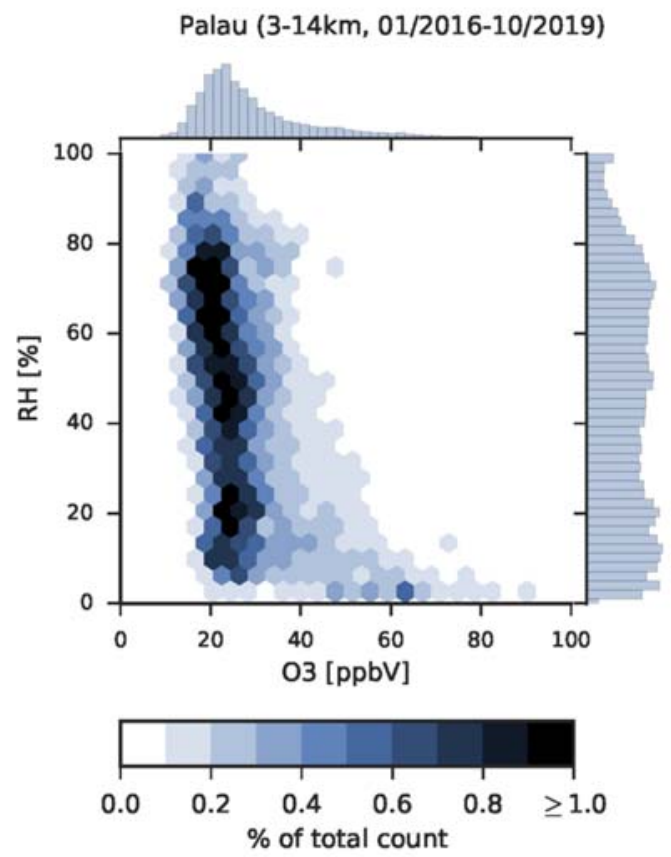

$\rightarrow$ Unique for Palau compared to other SHADOZ observations, but offers no ideal separation of background and layers. Additional analysis similar to Pan et al. 2015 was also unsuccessful.

Fig.6: $\mathrm{O}_{3}$ and $\mathbf{R H}$ anomalies from the above defined background and classification of air masses in a $3 \times 3$ grid.

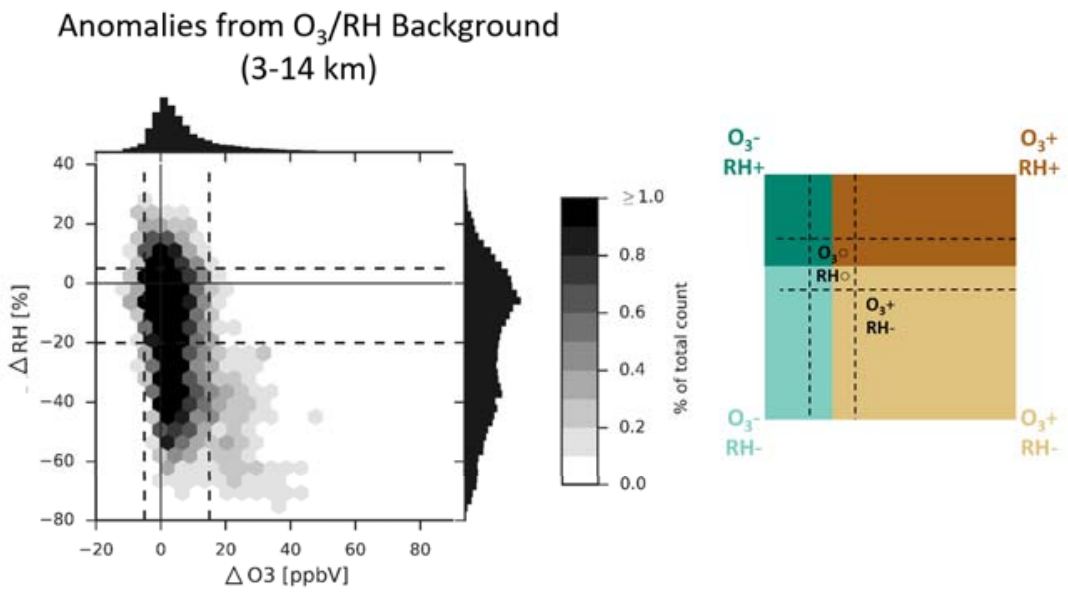

$\rightarrow$ Bimodality in RH anomalies: motivating classification in $\mathrm{O}_{3} \mathrm{RH}$ groups and thus constituting our air mass definition in the following.

Fig.7: Seasonal differences of air mass occurence (compare with "Seasonal Data Overview"). 


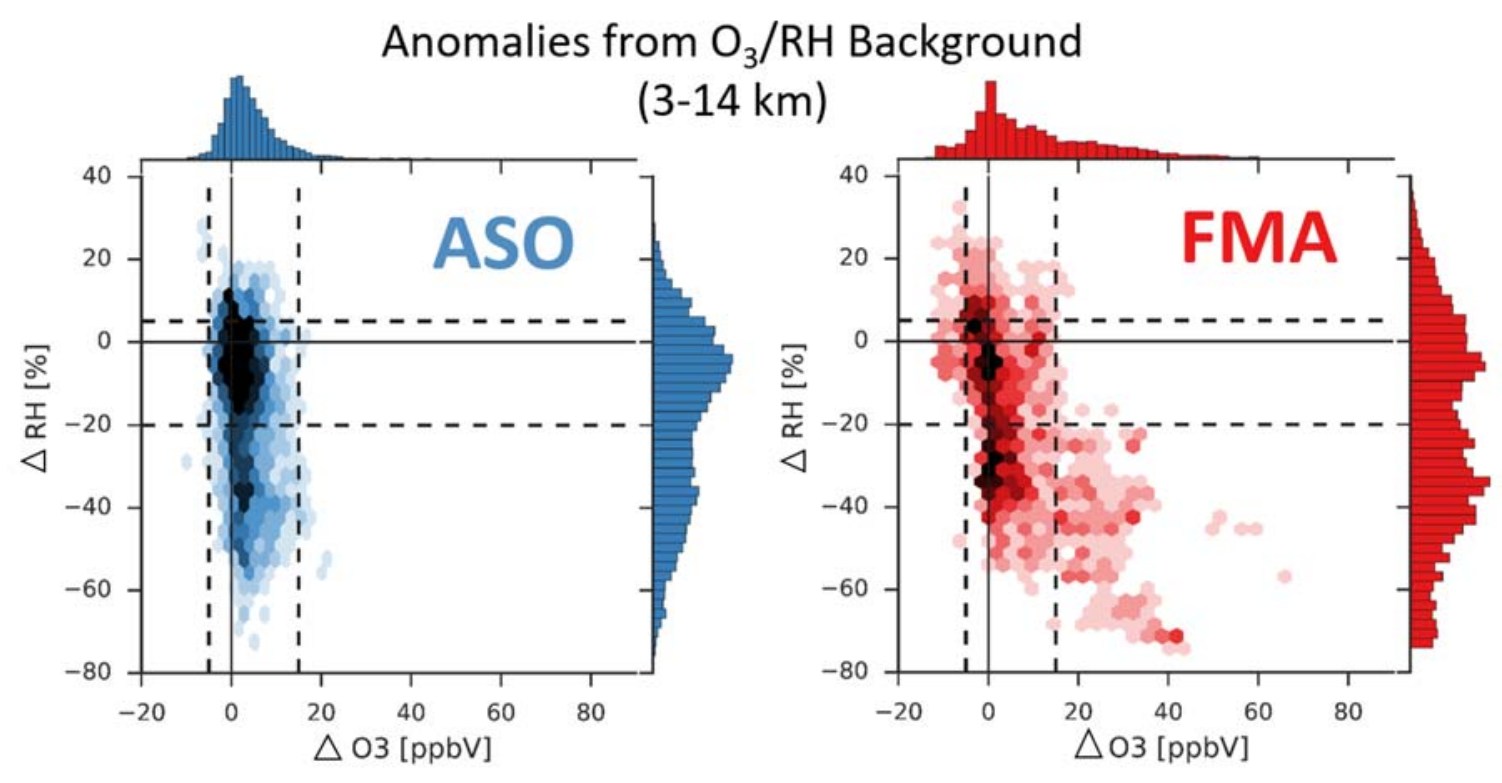

$\rightarrow \mathbf{O}_{3}$ oRHo: humid, $\mathrm{O}_{3}$-poor background occurs year-round, but dominates ASO.

$\rightarrow \mathbf{O}_{3}+\mathbf{R H}-:$ dry, $\mathrm{O}_{3}$-rich air masses are most frequent in FMA.

Fig.8: Heatmaps for the seasonal occurrence of air masses for all nine $\mathrm{O}_{3} R H$ anomaly groups, as defined above.

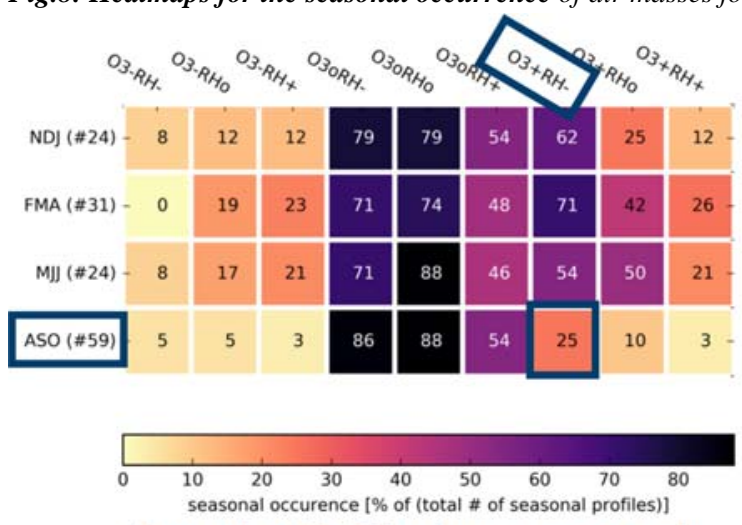

Example: $\mathrm{O} 3+\mathrm{RH}$ - air masses occur in $25 \%$ of all ASO profiles.

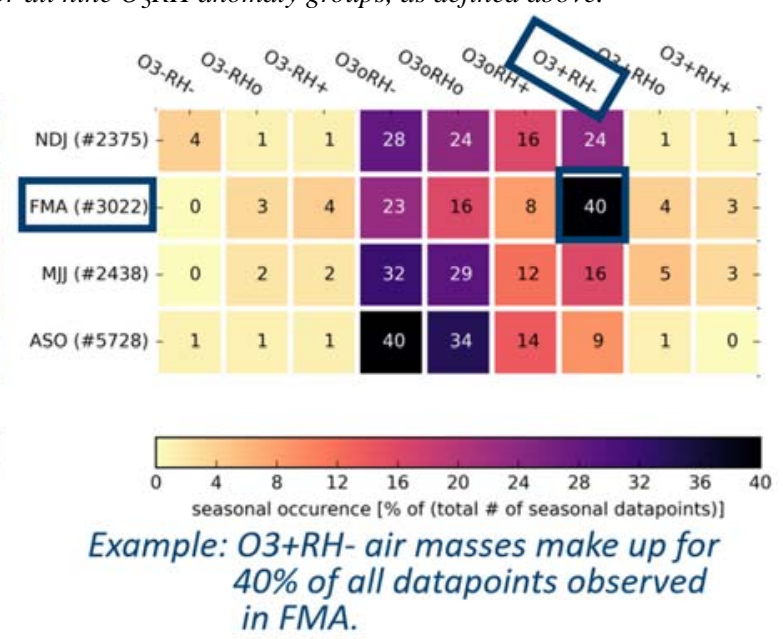




\section{TRANSPORT PATHWAYS AND PROCESSES}

Overarching questions: What are the major transport pathways to the TWP and can we identify the air mass origin with the observed $\mathrm{O}_{3} / \mathrm{RH}$ relation?

Fig.9: Schematic for transport pathways to Palau and the TWP on the zonal plane, color-coded by air mass group $\left(\mathrm{O}_{3} R H\right.$, see Background versus Layers).

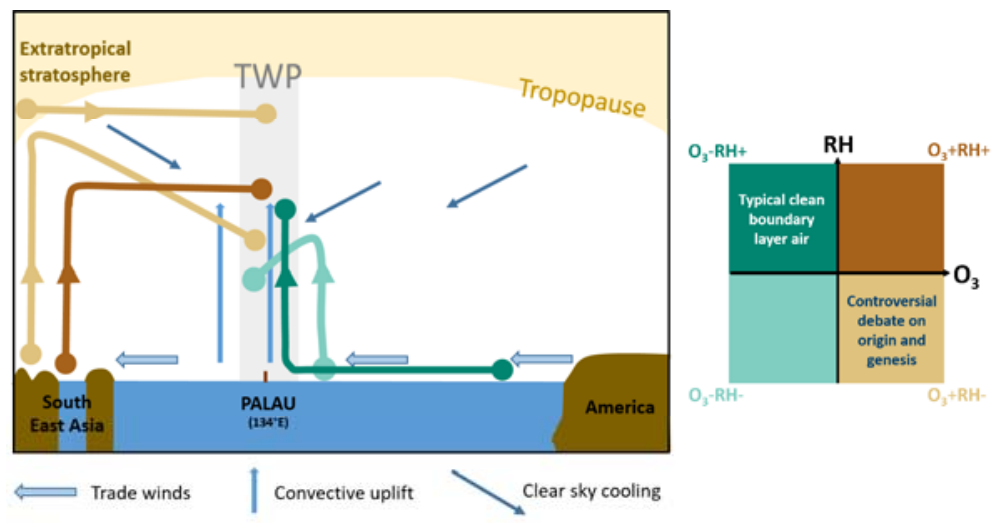

Backtrajectory analysis using the transport module of the fully Lagrangian Chemistry and Transport Model ATLAS (Wohltmann et al. 2010), driven by ERA5 reanalysis data, no diffusion, no convective model parameterization, 10-min timesteps, initialized from sounding data, focus on the $5-10 \mathrm{~km}$ altitude range.

Fig.10: 10-days backward trajectories by season for the 5-10 km altitude range (compare Seasonal Data Overview).

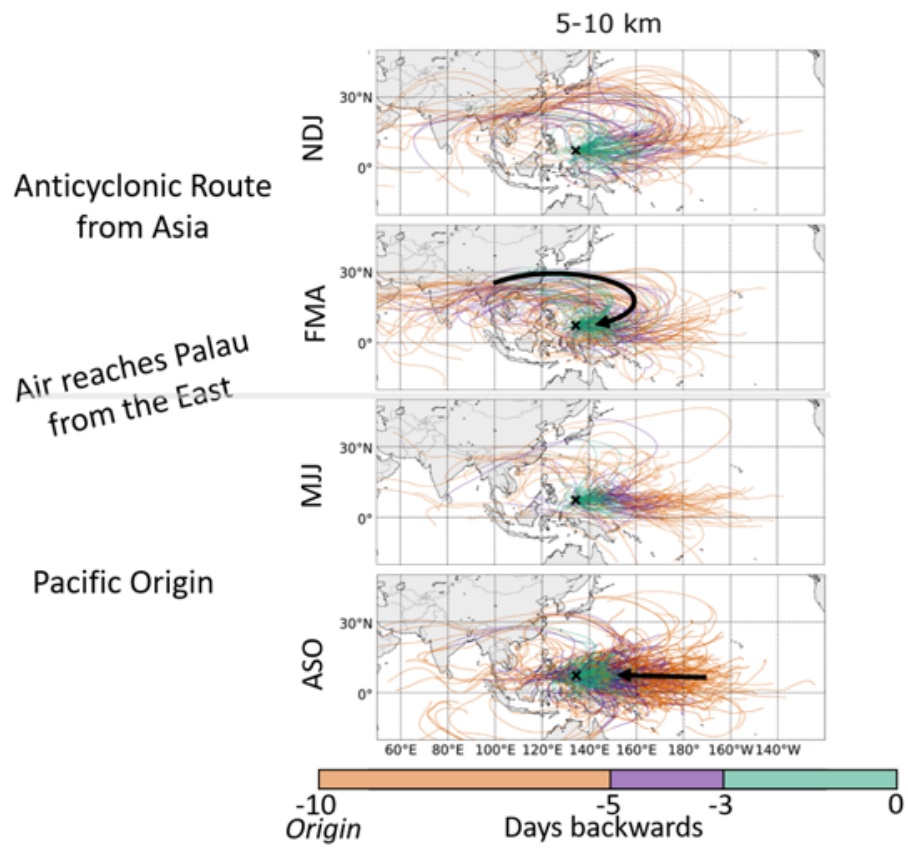

Fig.11: 5-days backward trajectory ending points (5-10 km), defined here as origin of air masses (due to lifetime of marine boundary layer $\mathrm{O}_{3}$ ) by season, color-coded by either $\mathrm{O}_{3}$ or difference in pressure altitude. 

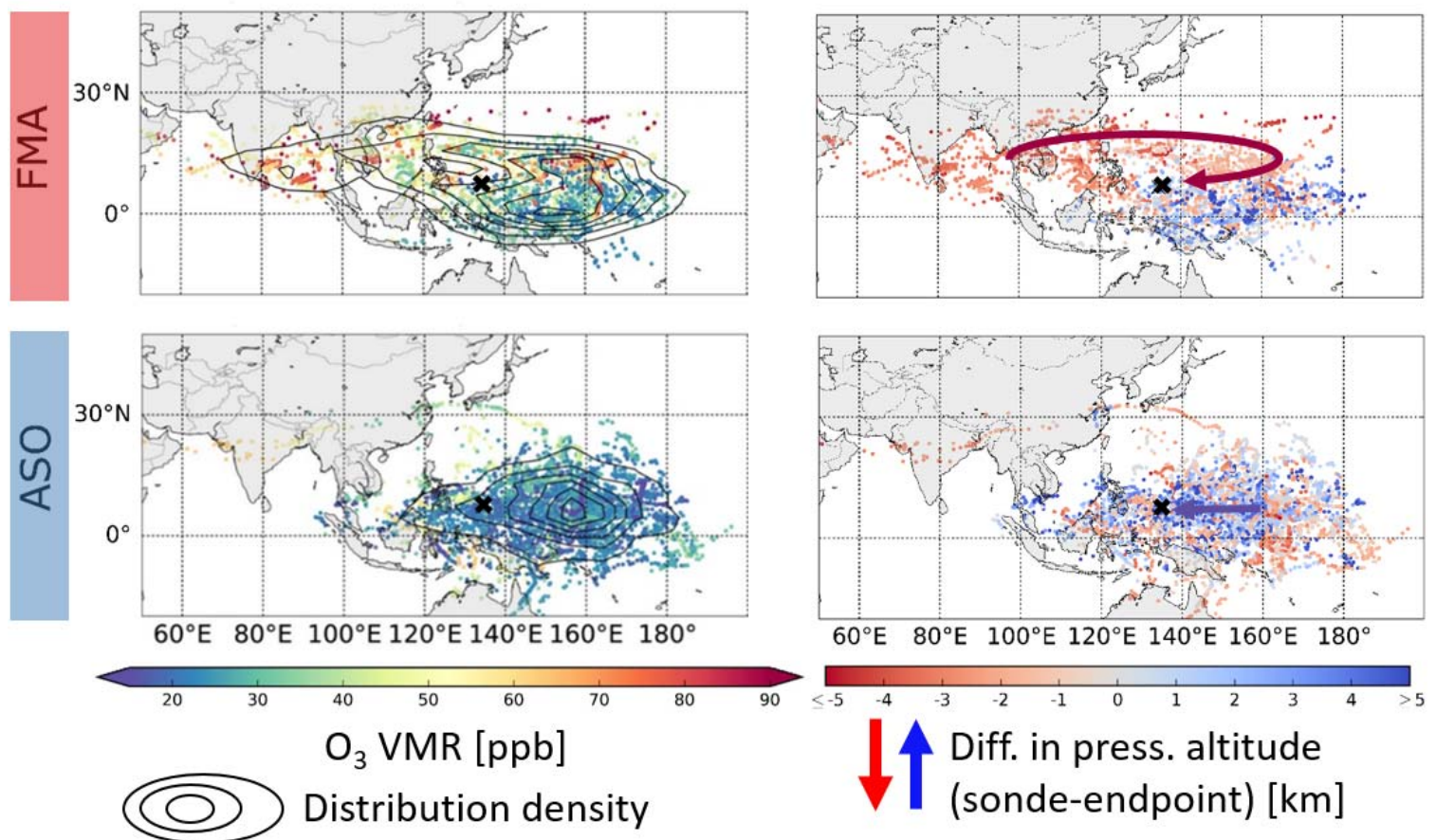

$\rightarrow$ Center of low $\mathrm{O}_{3}$ in both seasons East of Palau, secondary center of enhanced $\mathrm{O}_{3}$ in FMA, North of Palau from India to East China

\section{$\rightarrow$ Vertical displacement of air masses:}

- mainly in FMA, North of Palau, air masses descend towards the islands (anti-cyclonic route), consistent with the largescale descent within the Hadley circulation and subsequent dehydration

- ascent dominates ASO air masses, corresponding well with the proposed convective uplift.

Fig.12: 5-days backward trajectory ending points (5-10 km) selected by air mass group (see Fig.6 for definition).

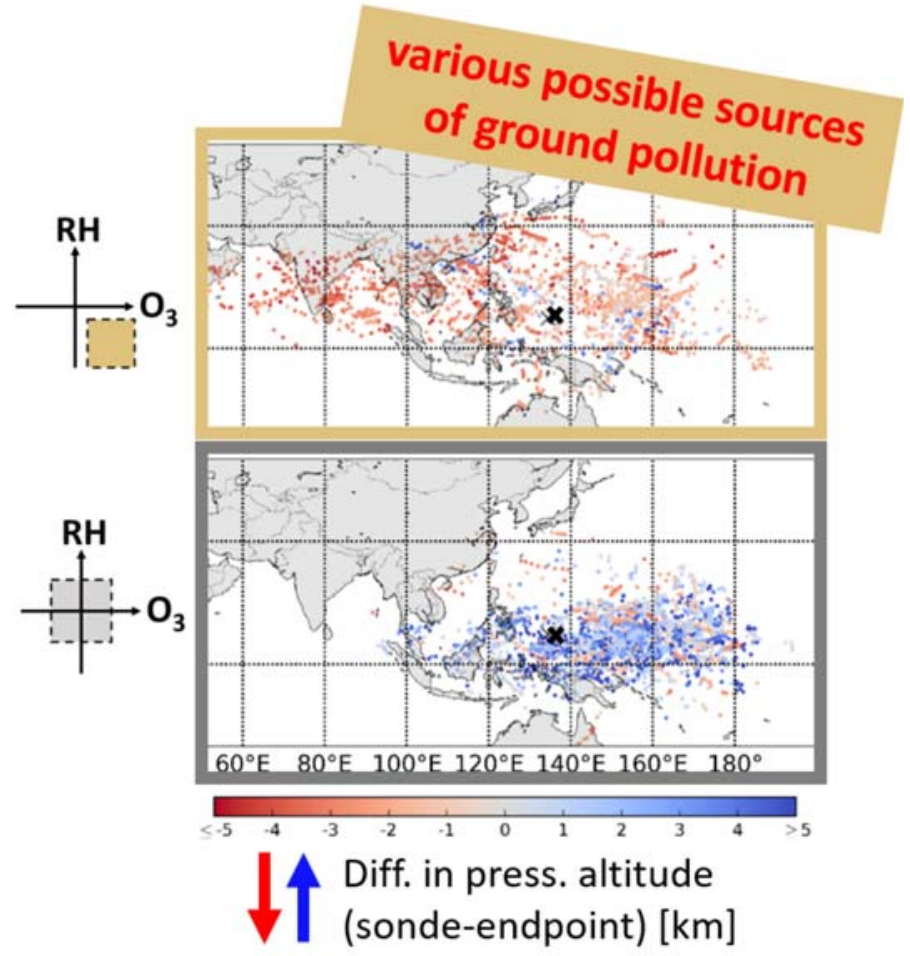

$\rightarrow$ Selection of trajectories for air masses identified as humid, $\mathrm{O}_{3}$-poor background $\left(\mathbf{O}_{3} \mathbf{0 R H o}\right)$ or dry, $\mathrm{O}_{3}$-rich $\left(\mathbf{O}_{3}+\mathbf{R H}-\right)$ anomaly from the background (see Air Mass Definition) separates air masses according to the processes controlling RH (convective uplift in blue, ASO, and dehydration during descent in red, FMA) and locates spacially separate source regions (see 
below).

- No indication for significant contribution of stratospheric air: Potential Vorticity analysis for all profiles (\#138, 5-10 $\mathrm{km}$ ) revealed essentially no air mass crossing the 1.5 PVU threshold for more than a day during 10 days backwards.

- Origin of air masses are areas of increased air pollution on the ground from industry or bio mass burning, speaking in favor for the pollution based origin.

\section{Summarized results:}

Dry, $\mathrm{O}_{3}$-rich: most frequent in FMA, $\downarrow$, tropical ASIA and Pacific

Humid, $\mathrm{O}_{3}$-poor: year-round, but dominant in ASO, $\mathbf{\uparrow}$, PACIFIC 


\section{SEASONAL DATA OVERVIEW}

First characterization of tropospheric $\mathbf{O}_{3}$ seasonality in the TWP with multi-year continuous timeseries.

Fig.13: Time-height-cross-section for tropospheric $\mathrm{O}_{3}$ Volume Mixing Ratio (VMR) observations from ECC ozone sondes, hatched contoured area highlight air masses with Relative Humidity $(\mathrm{RH})<30 \%$, arrows mark individual soundings, linear interpolation in between.

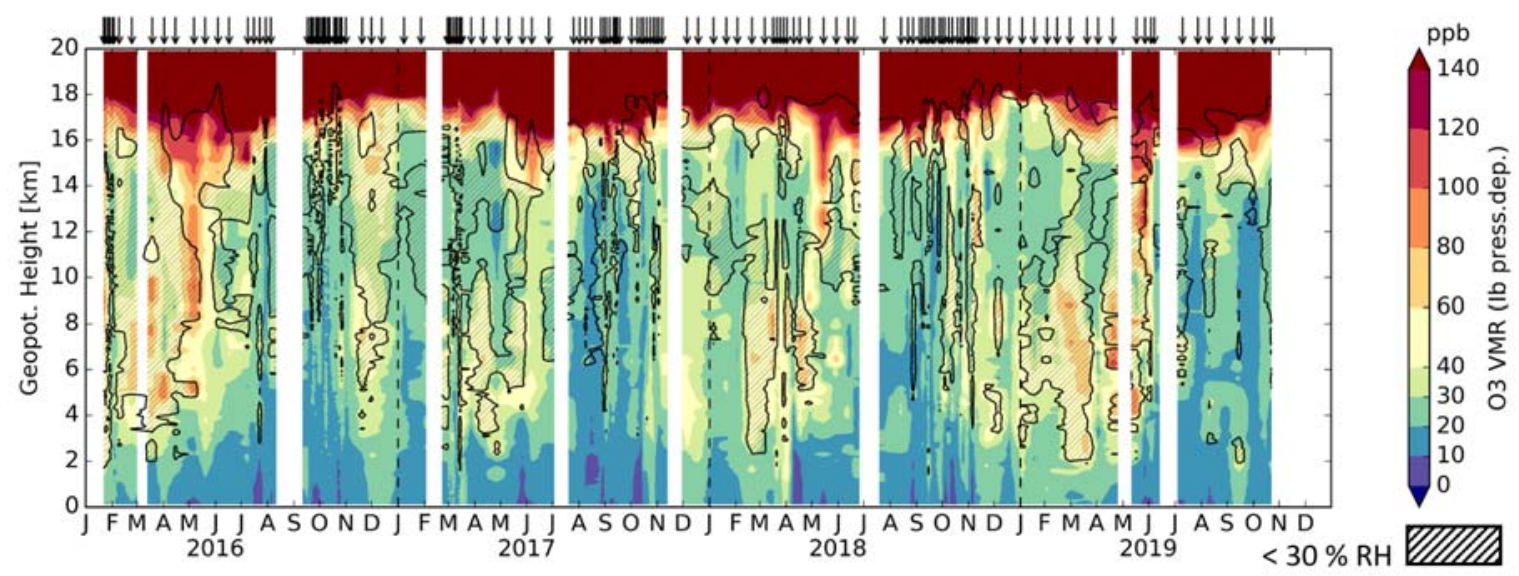

$\rightarrow$ Mid-tropospheric cycle: $\mathrm{O}_{3}$ minimum from July-October, layers of enhanced $\mathrm{O}_{3}$ from February-April, often anticorrelated with $\mathbf{R H}$.

$\rightarrow$ TTL cycle: fits tropopause height and temperature variations related to the seasonality of the Brewer Dobson circulation and enhanced high altitude convective outflow (Randel et al. 2007, Folkins et al. 2006).

Fig.14: Time-height-cross-section for monthly mean $\mathrm{O}_{3} \mathrm{VMR}$ and seasonal mean profiles.
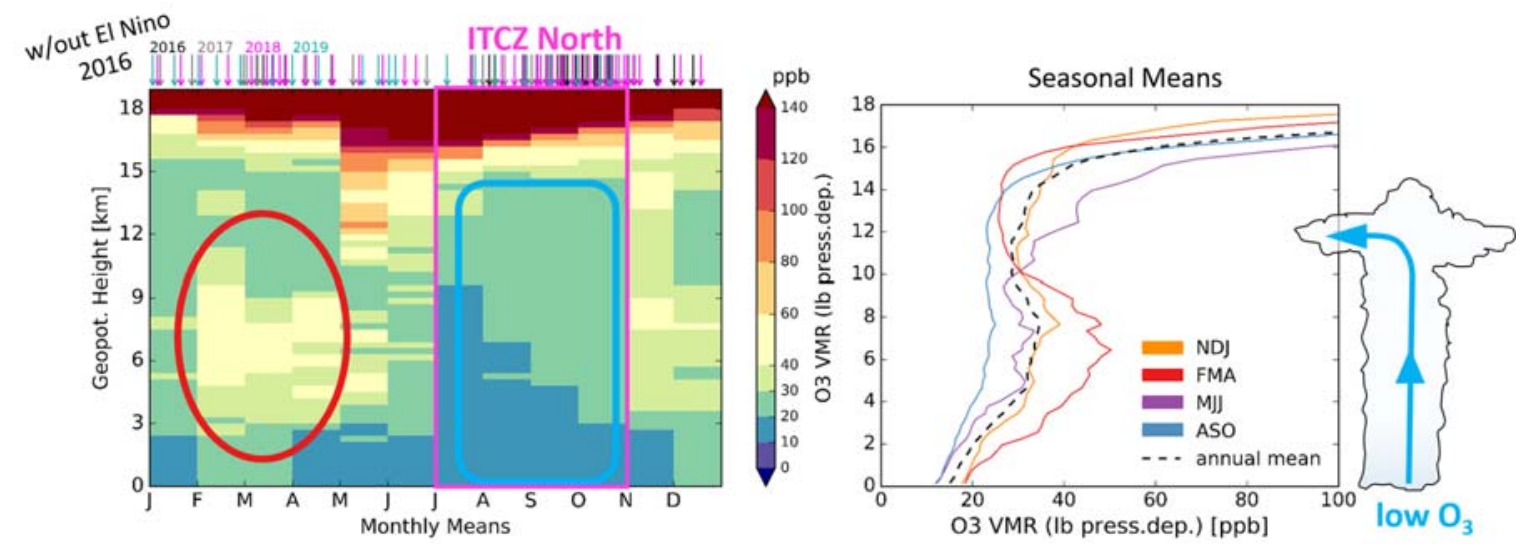

$\rightarrow$ Monthly means highlight the annual cycles: $\mathrm{O}_{3}$ minimum corresponds with the Intertropical Convergence Zone (ITCZ) located North of Palau.

$\rightarrow$ Annual mean: typical (tropical) "S-shape"

$\rightarrow$ Monthly means grouped according to similar shape:

4 distinct types of profiles (seasons):

NDJ -- November-December-January

FMA -- February-March-April

MJJ -- March-June-July 
ASO -- August-September-October

$\rightarrow$ Deep convective detrainment can explain upper dent in the "S" (10-14 km), between 5-10 km, or the belly of the "S": weak cloud-mass divergence, greatest anomalies from annual mean in ASO (background) and FMA (deviating layers, compare Fig.7,8). 


\section{TAKE AWAY MESSAGES}

- Four-year tropospheric $\mathrm{O}_{3}$ time series from balloone-borne measurements fills the observational gap in this key region of stratospheric entry.

- Using the data set, seasonal analysis, trajectory modelling and a statistical approach to distinguish air masses by $\mathrm{O}_{3} / \mathrm{RH}$ relation, we identified transport processes and pathways to the TWP:

\section{Humid, $\mathrm{O}_{3}$-poor}

Processes Convective background

Origin Pacific or local

Frequency Year-round, dominant in ASO

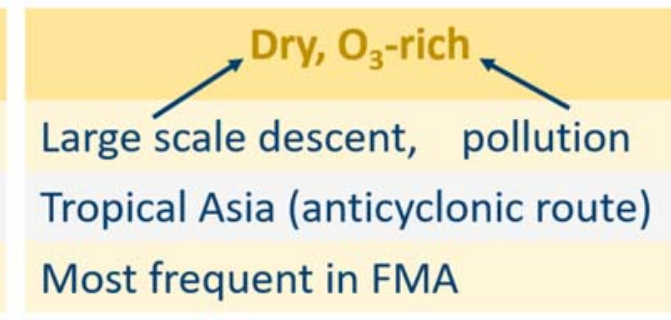

\section{OUTLOOK:}

- $\mathrm{PhD}$ thesis available, publication as paper in progress

- participation in the ACCLIP campaign, postponed to 2021 


\section{DISCLOSURES}

Major part of this work was funded under the EU-project StratoClim (www.stratoclim.org), additional funding was provided by the Alfred-Wegener-Institute. All data and code are available upon request.

We used ECMWF ERA5 data provided by the Copernicus Climate Change Service Climate Data Store for the trajectory analysis.

I want to acknowledge our logistical and scientific service partners in Palau, namely CTSI Logistics and CRRF, including our main local operator Sharon Patris, the Palau Community College and principal Patrick Tellei for the provision of space, but also technical "inhouse" support from the AWI mainly by Jürgen Graeser, but also impres GmbH with Ingo Beninga and Wilfried Ruhe, majorly involved in setting up and maintaining the station. 


\section{AUTHOR INFORMATION}

I am a Postdoc at the Alfred-Wegener-Institute in Potsdam, Germany, and just recently defended my PhD thesis, from which I present major results on my poster.

Feel free to contact me, I am happy and curious for new collaborations! 


\section{ABSTRACT}

Motivated by previous measurements of very low tropospheric ozone concentrations in the Tropical West Pacific (TWP) and the implied low oxidizing capacity of this key region for transport into the stratosphere (e.g. Rex et al. 2014), we set up an atmospheric research station in Palau $\left(7^{\circ} \mathrm{N} 134^{\circ} \mathrm{E}\right)$. Our analysis of regular balloon-borne tropospheric ozone observations at Palau from 01/2016-10/2019 confirms the year-round dominance of a low ozone background in the mid-troposphere. Layers of enhanced ozone are often anti-correlated with water vapor and occur frequently. Moreover, the occurrence of respective layers shows a strong seasonality. Dry and ozone-rich air masses between 5 and $10 \mathrm{~km}$ altitude were observed in $71 \%$ of the profiles from February until April compared to $25 \%$ from August until October. By defining monthly atmospheric background profiles for ozone and relative humidity based on observed statistics, we found that the deviations from this background reveal a bimodal distribution of RH anomalies. A previously proposed universal bimodal structure of free tropospheric ozone in the TWP could not be verified (Pan et al. 2015).

Back trajectory calculations confirm that throughout the year the mid-tropospheric background is controlled by local convective processes and the origin of air masses is thus close to or East of Palau in the Pacific Ocean. Dry and ozone-rich air originates in tropical Asia and reaches Palau in anticyclonic conditions over an area stretching from India to the Philippines. This supports the hypothesis of several studies which attribute ozone enhancement against the low ozone background to remote pollution events on the ground such as biomass burning (e.g. Andersen et al. 2016). A potential vorticity analysis revealed no stratospheric influence and we thus propose large-scale descent within the tropical troposphere as responsible for dehydration of air masses on their way to Palau. 


\section{REFERENCES}

D. C. Anderson et al. A pervasive role for biomass burning in tropical high ozone/low water structures. Nature Communications, 7(1):10267, April 2016. ISSN 2041-1723. doi: 10.1038/ncomms10267. URL http://www.nature.com/articles/ncomms10267. $2,53,63,78,80,82,92,94,96,107$

A. E. Dessler and K. Minschwaner. An analysis of the regulation of tropical tropospheric water vapor. Journal of Geophysical Research: Atmospheres, 112(D10), May 2007. ISSN 01480227. doi: 10.1029/2006JD007683. URL http://doi.wiley.com/10.1029/ 2006JD007683. 12, 80, 92, 107

I. Folkins, P. Bernath, C. Boone, G. Lesins, N. Livesey, A. M. Thompson, K. Walker, and J. C. Witte. Seasonal cycles of O3, CO, and convective outflow at the tropical tropopause. Geophysical Research Letters, 33(16):L16802, 2006. ISSN 0094-8276. doi: 10.1029/2006GL026602. URL http://doi.wiley.com/10.1029/2006GL026602. 60,106

H. Hayashi, K. Kita, and S. Taguchi. Ozone-enhanced layers in the troposphere over the equatorial Paci c Ocean and the influence of transport of midlatitude UT/LS air. Atmospheric Chemistry and Physics, page 14, 2008. 42, 61, 62, 74, 75, 80, 82, 85, 92, 94, 106

W. J. Randel, M. Park, F. Wu, and N. Livesey. A Large Annual Cycle in Ozone above the Tropical Tropopause Linked to the Brewe-Dobson Circulation. Journal of the Atmospheric Sciences, 64(12):4479 \{4488, December 2007. ISSN 0022-4928, 1520-0469. doi: 10.1175/2007JAS2409.1. URL http://journals.ametsoc.org/doi/10.1175/ 2007JAS2409.1. 2, 42, 59, 60, 106

M. Rex, I. Wohltmann, T. Ridder, R. Lehmann, K. Rosenlof, P. Wennberg, D. Weisenstein, J. Notholt, K. Kruger, V. Mohr, and S. Tegtmeier. A tropical West Pacific OH minimum and implications for stratospheric composition. Atmospheric Chemistry and Physics, 14(9):4827 \{4841, May 2014. ISSN 1680-7324. doi: 10.5194/acp-14-4827-2014. URL https://www.atmos-chem-phys.net/14/4827/2014/. 1, 2, 3, 14, 17, 22, 23, 26, $27,32,36,38,47,80,97,102,106,107$

I. Wohltmann, R. Lehmann, and M. Rex. The Lagrangian chemistry and transport model ATLAS: simulation and validation of stratospheric chemistry and ozone loss in the winter 1999/2000. Geoscienti c Model Development, 3(2):585 \{601, November 2010. ISSN 1991-9603. doi: 10.5194/gmd-3-585-2010. URL https://www.geosci-model-dev. net $/ 3 / 585 / 2010 / .45,46$
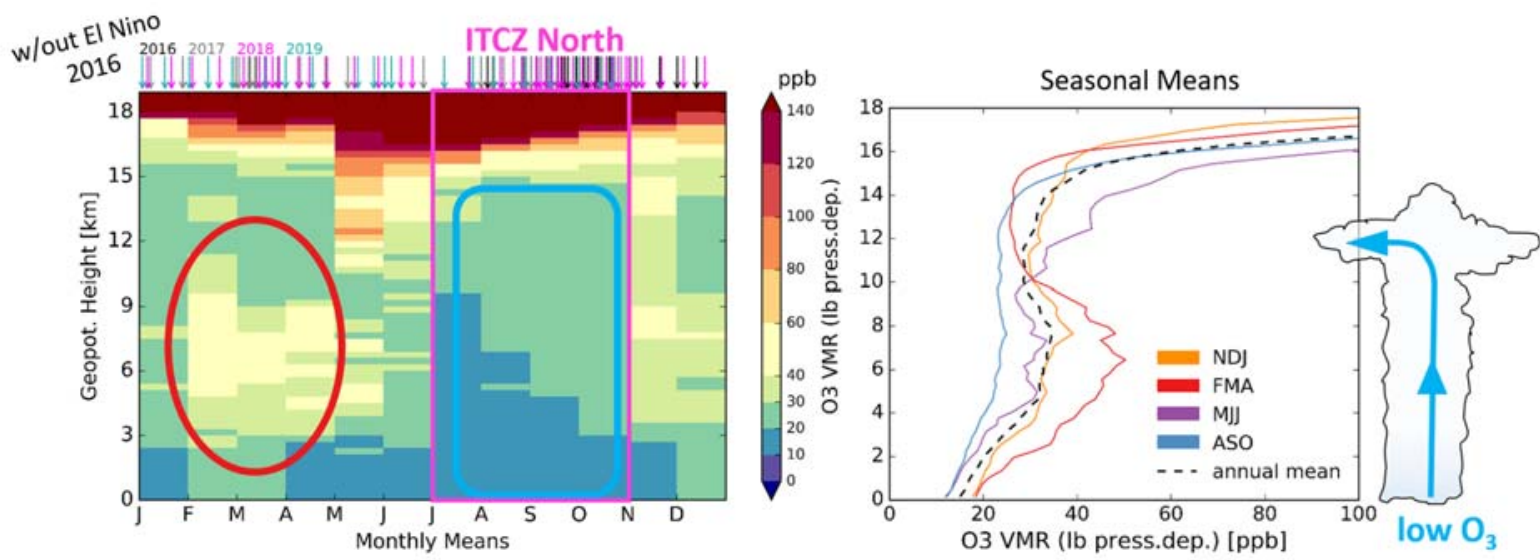